\title{
Multifaceted diagnostic inference process for identifying the causes of self-ignition engine faults resulting from PM sediments
}

\begin{abstract}
Optimization of the fuel combustion process in a self-ignition engine with the multi-stage HPCR injection system sets the main trends in research on the thermodynamic stability of fuels, and the mechanisms of PM formation. The stages were indicated of the multifaceted diagnostic inference on the causes of failures of a turbocharger with variable geometry (VTG) which occur as a result of PM sedimentation in the nozzle area. An evaluation of the engine performance was conducted using a dedicated tester and an additional recording of the injector coil current characteristics with parallel readings of the fuel pressure variation in the reservoir. The indicated procedure established the underlying cause of the VTG compressor failure despite the absence of a recorded error code.
\end{abstract}

Key words: VGT turbocharger, PM particulates, diagnostic tester, spectral analysis, error codes

\section{Introduction}

The chemical formula of motor fuels is constantly evolving due to the requirements for combustion processes improvement, engine components cleanliness, and environmental protection, including propulsion system development [12].

Optimization of the fuel combustion process in a selfignition engine with the multi-stage hydrocarbon fuel injection and fuels with added FAME biocomponents sets the main trends in fuel thermodynamic stability research, as well as the development of engine structures equipped with HPCRS. Oxidation resistance is one of the most important properties of fuel containing FAME components because of their low stability, resulting in products that jeopardize the sound functioning of the engine systems [13].

Fuels for compression-ignition engines, which meet the high requirements of modern diesel engine units equipped with HPCR high pressure fuel injection systems and catalytic exhaust after-treatment systems, must have appropriate physicochemical and utility properties.

The evolution of fuel quality, including biocomponents, requires continuing research which allows the identification of the quality and usability issues and indicates the possibilities for solving them. One of the important quality parameters closely related to the structure-group composition of fuels intended to power engines with self-ignition is their tendency for sediment formation. Some fuel properties such as high viscosity, low volatility, olefin content, aromatic compounds, and FAME biocomponents facilitate the formation of carbon deposits in the injector hole area, the combustion chamber, the turbocharger and the DPF system. A gradual growth of PM layers results in the loss of proper fuel spraying capability, the immobilization of the VTG turbocharger nozzle positioner, and the flue gas duct blockage in the DPF system [13].

The effects of these processes result in the occurrence of engine failures related to the record in the error code controller, the MIL indicator signaling, and switching to the engine's substitute operating characteristics. The complex nature of the error codes recording requires undertaking a multifaceted diagnostic inference process, as illustrated in the example of determining the causes of damage to a turbocharger with variable geometry (VTG). The profound analysis of the error codes recorded in the controller's memory conducted with the use a dedicated tester, along with a comparative evaluation of the "frozen frame" record and the current characteristics of the injector coil supply system against the backdrop of the fuel pressure record in the reservoir, allows to determine the cause of the fault.

\section{Diagnostics of the self-ignition turbocharged engine (VTG)}

The EDC system developed by Bosch is designed to control a self-ignition engine. This system, which monitors the turbocharger operation and controls the timing and the opening phases of the injectors, has been subject to continuous modifications (EDC 15, EDC 16, EDC 17) due to the introduction of further versions of the HPCRS. The vehicle's IT bus is used to communicate the EDC with the other controllers installed in the vehicle, and also to cooperate with external diagnostic testers through the OBD connector. In the case of the G9U 2.2 DCI engine which is being analyzed, the vacuum control system was used for the VTG turbocharger, consisting of a vacuum pump, a reservoir, an electrovalve, and an actuator which controls the nozzle positioner. The vehicle test run demonstrated a significant decrease in power and low acceleration values on each gear, indicating the VTG turbocharger damage. However, the identification of the faults of the indicated engine subassembly must be confirmed by a parametric analysis conducted with the use of the Clip probe with a dedicated interface for the vehicle of this make (Fig. 1) [9].

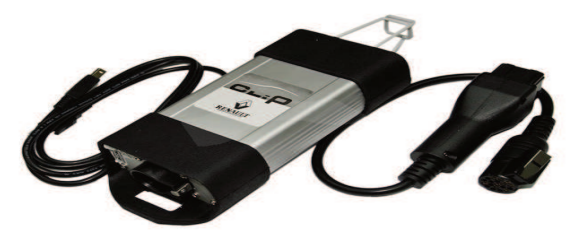

Fig.1. CLIP probe with the interface unit

The DF 301 error code referring to the "inlet air circuit" has been recorded in the controller memory. In the "infor- 
mation" tab, the 1.DEF explanation indicates the low mass air flow in the engine air intake system. The "frozen frame" parameter reading was performed for the analysis of the engine's operating parameters at the time when the controller detected the fault (Fig. 2), which occurred at full load of the engine.

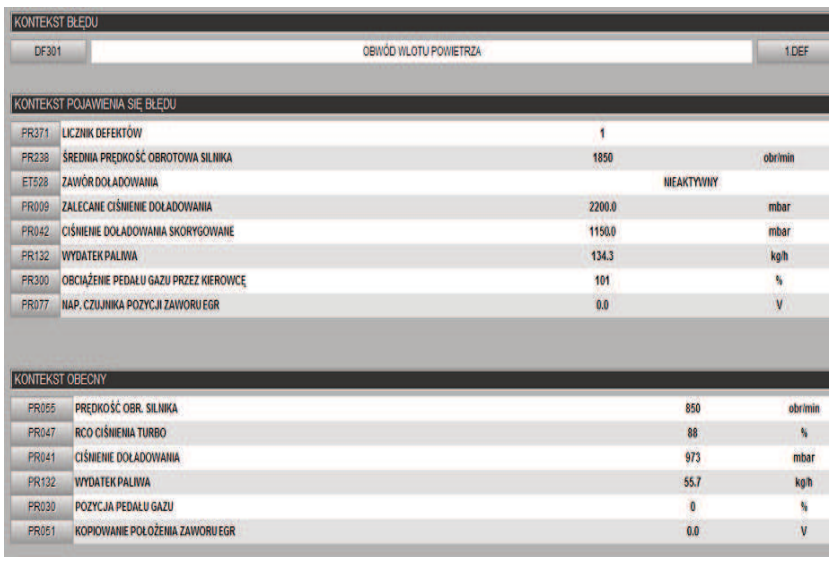

Fig. 2. Frozen frame recording when DF 301 error occurs

The difference was observed between the desired supercharging pressure values and the actual value generated by the pressure sensor in the air intake system behind the turbocharger. There was a large discrepancy between these values, with the difference increasing as the engine load increased. The condition is not always signaled by the MIL indicator, as it responds to the specificity of the engine controller software (EDC) [6]. The software differences correspond not only to the injection or turbocharger map, but also to the autodiagnostic system and the threshold value for error generation. Therefore, in case of a difference in supercharging pressures - actual and expected, the MIL indicator will not light up in each case. It is also necessary to know about the possible modifications to the original software for engine tuning purposes or for blocking a DPF bit frame or EGR valve [14]. Thus, checking the actual and expected supercharging pressures is an effective method for the initial confirmation of a fault in the engine charging system.

An important control parameter is also the voltage at the signal output of the flow meter, which allows to determine the possible power supply leaks when the turbocharger is operating properly. In the analyzed example (Fig. 3), with the air tight intake system, too low voltage of $3.56 \mathrm{~V}$ occurred, compared to the required voltage of approx. $5 \mathrm{~V}$ at the specified rotational speed.

The analysis conducted directly points to the possibility of VTG turbocharger's nozzle seizure as a result of accumulated particulate matter sediments, thus limiting their mobility. The tested engine did not show excessive lubricating oil consumption, which excludes the possibility of the sediments being formed from the residue of the excess lubricant burned. In this case, it is necessary to extend the scope of the diagnostic inference to the fuel injection regularity issue in the HPCR system despite the absence of an error indicating a system fault. The representative parameters of the system, primarily the corrective dose of the in- jectors, have been checked to assess the correctness of their operation. The increase in the corrective doses affects the excessive formation of solid particles, which also settle inside the turbine and contribute to the nozzle seizure. [7]. The measurement (Fig. 4) showed a large difference in the corrective doses of the injectors, but this does not directly imply their emergency condition. However, this fact is not indifferent to the VTG compressor and is undoubtedly one of the reasons behind the blocking of the nozzle controlling mechanism. Dose differences between injectors may also be related to the dynamic tightness of individual engine cylinders. The high value of the fuel correction for the $3 \mathrm{rd}$ cylinder is noteworthy.

\begin{tabular}{|c|c|c|c|}
\hline PREE & PREGOOSCC OER SLIIIA & 298 & otrmin \\
\hline PRORE & TEUPERATURA POWETRRAA & vis & \\
\hline PRRYS & 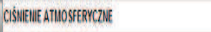 & 978 & mitar \\
\hline PRl41 & 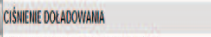 & Meg & mbar \\
\hline PRIOQ & 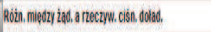 & 472 & Ppo \\
\hline PRAG7 & 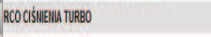 & 3i & 1 \\
\hline PRI2D & RCoanoruegr & 6 & 3 \\
\hline PRIX2 & WOATEKPAWNA & 172.2 & kqu \\
\hline ET212 & 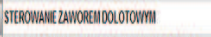 & \multicolumn{2}{|c|}{ MEATWWWY } \\
\hline El211 & 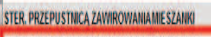 & \multicolumn{2}{|c|}{ HIAATTMUYY } \\
\hline PRO73 & 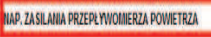 & 136 & y \\
\hline PRO11 & 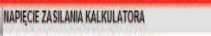 & 144 & y \\
\hline PRP15 & 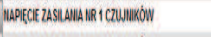 & 5.0 & v \\
\hline PR216 & 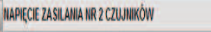 & 5. & y \\
\hline
\end{tabular}

Fig. 3. Low voltage level of the flowmeter measuring system

\begin{tabular}{|c|c|c|c|}
\hline PRO71 & 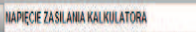 & & v \\
\hline ETOIO & 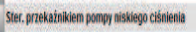 & \multicolumn{2}{|c|}{ Mearrwair } \\
\hline PR055 & PREDOOSECORR, SLIIIIRA & 850 & otrimin \\
\hline ETा104 & 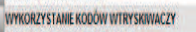 & \multicolumn{2}{|c|}{ TAK } \\
\hline PR038 & 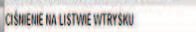 & 31 & bar \\
\hline PQMO2 & 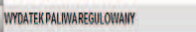 & 1500 & mints \\
\hline Pro17 & WOATEKPALMA & 94 & mmsep \\
\hline Pr2033 & 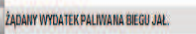 & 78 & $\mathrm{~mm} 3 \mathrm{se}$ \\
\hline PR683 & 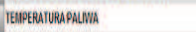 & 40.9 & " \\
\hline PQ830 & 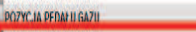 & 0 & 1 \\
\hline PR334 & KOREKCLA WYOATUUPALWWAWCYUIORE! & 29 & mmsep \\
\hline PRA05 & 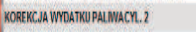 & 45 & minstep \\
\hline PRA06 & 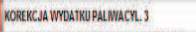 & 3 & $\mathrm{~min} 34$ \\
\hline PR365 & 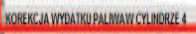 & is & minsep \\
\hline PR213 & 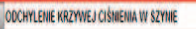 & 0.0 & bar \\
\hline
\end{tabular}

Fig. 4 Correction doses control for CR injectors.

An EDIA-5 analyzer (Fig. 5) which allows for the registration of injection control signals was used to investigate the causes of the fault. [11]. It is possible to view the control current characteristics for the four injectors with the reference of these values to the high pressure fuel sensor signal on the fuel rail (Fig. 6). The measurement allows the analysis of signal timing, amplitude and high pressure rise. Profound observation and interpretation of the injection timing characteristics and the pressure drop allows for the quick fault diagnosis.

The recorded characteristics show the high pressure maintenance conditions for the 3rd cylinder injector over the extended periods of time, suggesting the possibility of "clogging the atomizer openings". In this case, one aspect is worth noting of the injector damage condition in the absence of fault indications generated by the MIL indicator [15]. Contaminated fuel and improper filtering quality lead to permanent defects of the injector's ball control valve, 
which cannot close the cross-channel leakage despite the EDC controller's failure to control the valve. The lower pressure in the control chamber of the injector causes an uncontrolled fuel injection. In this case, the controller will not register any fault, and the excess fuel contributes to the exhaustion smoke increase. Despite such a serious fault in the system - the MIL indicator on the instrument cluster [14] will not be activated.

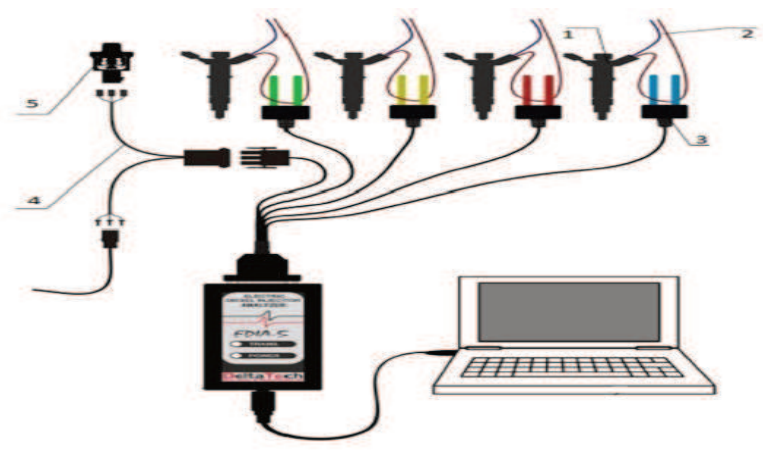

Fig. 5. Connection diagram of EDIA-5 analyzer [11]. 1 - injector, 2 injector wires or dedicated connector, 3 - measuring probe, 4 - pressure sensor connection cable 5 - pressure sensor

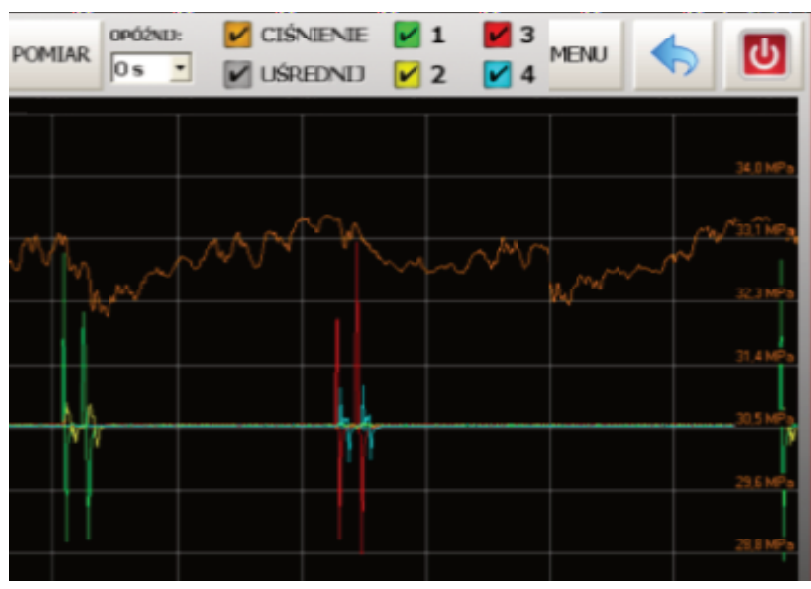

Fig. 6. Current characteristics of injector coils and pressure in the fuel rail.

The last step is to erase the errors recorded in the controller's memory. This is an action that must always be performed after a repair or replacement of damaged components. Disassembly of the turbocharger confirmed the expected excess of the sediment in the lever and steering vanes area, and also the excessive deposits were found in the injector outlet zone (Fig. 7). After error deletion and a test run, the tester record showed no error codes.

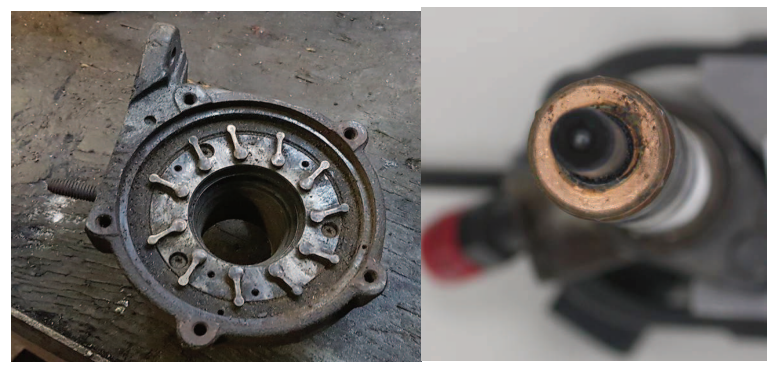

Fig. 7. Residual sediments in the area of the levers positioning the exhaust nozzle blades and in the zone of injector outer openings
The above stages of the engine diagnostic process indicate the need to extend the interpretation of the fault states resulting from the recorded error codes with the use of a dedicated diagnostic kit. In this case replacing or repairing the VTG turbocharger would lead to a short-term improvement in the engine's operating condition, as the major malfunction results from improper fuel injection by the injector due to the sediment deposition in the exhaust zone. It is therefore desirable to fully visualize the performance parameters of interdependent systems and not to focus solely on the identified errors codes. The diagnostician should have the necessary knowledge to allow for accurate assessment of the engine damage, especially in the case of multi-mode functional analysis of engine systems.

\section{Causes of IDID formation}

The dangers arising from the formation of IDIDs involve the limitation to operation of the internal injectors' work units or their total blockage which results in the hydraulic dysfunction of these important engine components.

FAME's share in the diesel fuel also contributes to the formation of IDID by acid impurities, formed by the autocatalytic division of fatty esters with metal ions $[1,2]$. Deposits formed this way can cause the surfaces of the interlocking elements to stick together, and intensify the corrosion processes. [8].

Particularly susceptible to the formation of the underlying sediments are PIBSI (Polyisobutylene bis Succinic Anhydride) with a high primary amine content in interaction with carboxy dimers of fatty acids. The resulting deposits are not soluble in commonly used organic solvents, which makes it difficult to analyze and determine their chemical structure.

Previous studies have also shown the potential for the formation of IDIDs from oxidation products of fuels. These products may especially occur in unstable diesel fuels containing FAME or may be a result of the aging of fatty acid esters present in lubricants [3, 4]. Multifunctional detergent-dispersant packs for diesel fuels, which contain a lot of additives, can interact and exhibit incompatibility manifested by turbidity and delamination. These issues require research into the component compatibility and stability.

It should be emphasized that the multifunctional detergent-dispersant additive package consists of a lubricant component, a corrosion inhibitor, a demulsifier, an antifoam additive, a cetane boost additive, an oxidation inhibitor, and a biocide.

The progress in the technology of detergent dispersant additives and their dosing level solves many of the problems discussed [2].

The multifunctional detergent dispersant package for advanced diesel engines must fulfill many functions protecting the HPCR high pressure fuel injection systems against internal IDIDs, atomizer blockage, wear and seizure of the high pressure fuel pump and also against corrosion of the fuel system. In addition, it should protect diesel fuel from oxidation, demonstrating the ability to wet metal surfaces and create a protective film that prevents highly adherent deposits and lacquers from settling, thereby keeping multi-turbo injectors clean [8]. 


\section{Spectral analysis of sediments}

Spectral analysis was performed of sediments from the fuel outlet openings of the HPCR injectors and from the turbocharger exhaust nozzle levers in order to determine the PM composition and their causes.

In the microscopic analysis of the deposit collected from the levers (Fig. 8), the sediment grains were observed, which were stained with a tarry substance. The sediment from the injection zone of the 3rd cylinder injector was characterized by a finer and "dry" structure with a visible fraction of the mineral material. The XRF ED X-ray fluorescence spectra were taken from the Oxford Instruments ED 2000 recorder, while the infrared IR spectra (FTIR) were recorded on the BIO-RAD FTS 175.

XRF (X-ray fluorescence) method was applied in the qualitative analysis and the sample of the sediments was taken after washing the analyzed zones with hexane (Fig. 9). On the basis of the assessment of band intensity changes for the identified elements, a qualitative assessment of the sedimentation was conducted. The presence of metals such as iron, zinc, chromium, nickel, and copper was found in the analyzed sediments. In addition, the presence of such elements as calcium and phosphorus and sulfur was noted. The presence of zinc, calcium and phosphorus results from the engine oil degradation, including the additive package. In addition, depressants also contain iron ions [8]. In the XRF spectrum for the sediments taken from the levers, a high intensity of iron bands was recorded. These impurities are mainly due to the corrosion processes of steel elements, whose structure is more susceptible to corrosive FAME. The relatively high intensity of the calcium and zinc bands was noted, indicating engine oil contamination as well as a significant share of the spectrum indicating nickel.
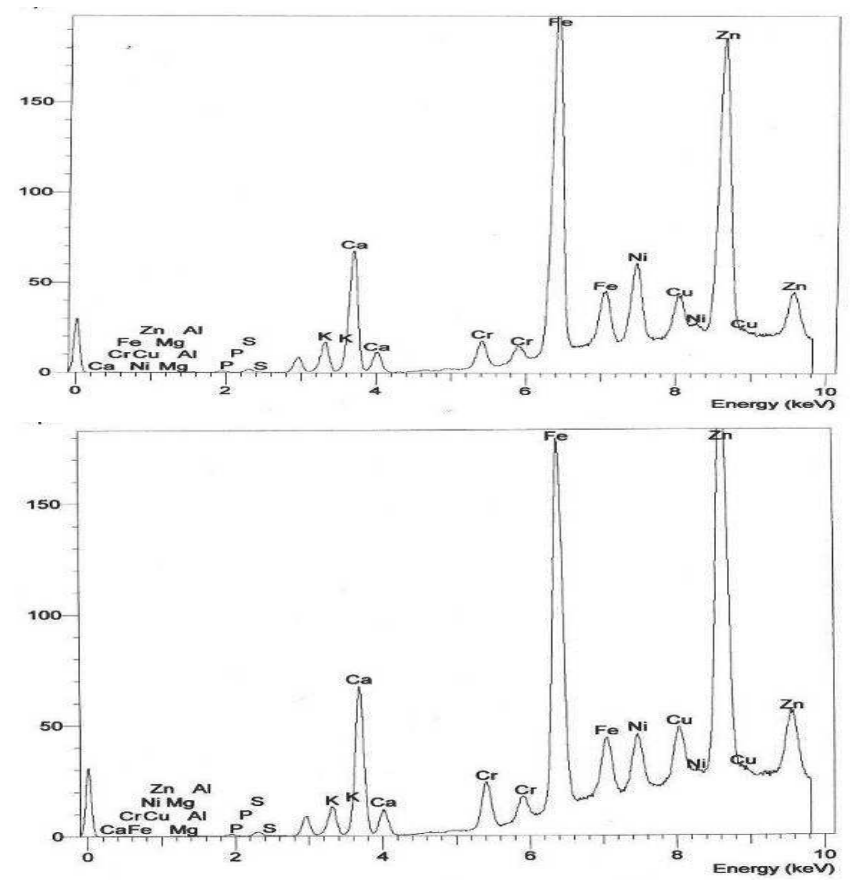

Fig. 8. XRF spectrum for sediments from the injector openings and nozzle levers

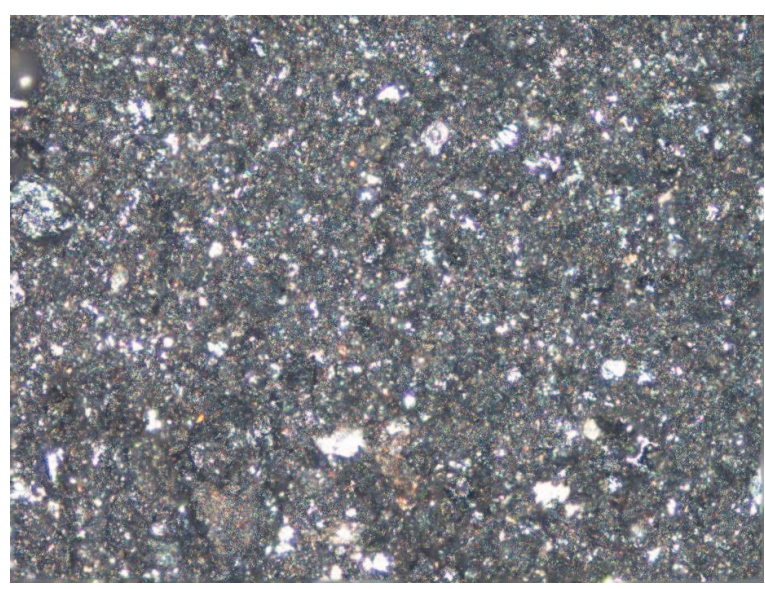

Fig. 9. Microscope image (magnification $100 \times$, reflected light) of the sediment collected from the exhaust nozzle levers

After the sediments from the outer surface of the analyzed zones were washed with chloroform, the sample was analyzed in the infrared spectrum. The fuel residue and the engine oil residue were observed, as well as degradation products. The IR spectrum for the substances isolated in the 3rd opening of the injector is poorer (Fig. 10). At first a comparative analysis was conducted of hydrocarbon bands, i.e. the range of wave numbers: $2850-3000 \mathrm{~cm}^{-1}, 1464$ $\mathrm{cm}^{-1}, 1377 \mathrm{~cm}^{-1}, 722 \mathrm{~cm}^{-1}$ [10]. In both cases, the background was more raised, which is related to the presence of soot. In addition, vibration bands typical for hydroxyl groups (about $3400 \mathrm{~cm}^{-1}$ ) are present, which may be derived from the absorbed water, and also from the alcohol and carboxylic acids structures [10].

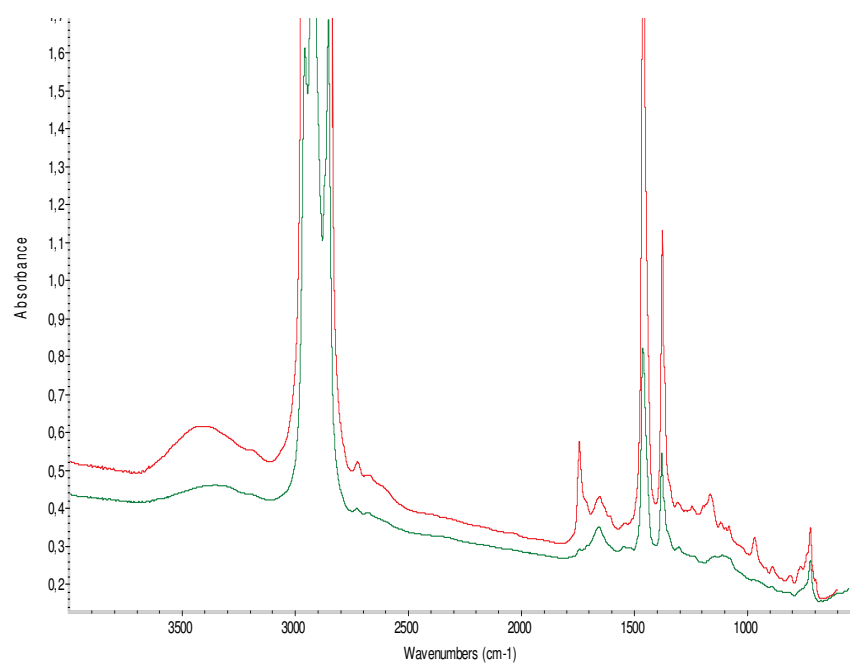

Fig. 9. Infrared spectrum of the soluble sediment from the injector openings (green) and nozzle levers (red)

The band in the range of about $1655 \mathrm{~cm}^{-1}$ in the diagnostic area of $2000-1600 \mathrm{~cm}^{-1}$ is also intensive, which indicates the presence of oxidation processes of organic compounds to carbonyl and carboxylic structures. The effects of these compounds on nitrogen oxides are related to the presence of hydrated carboxylic acid salts. These substances may also be derived from the oxidation and degra- 
dation processes of the basic additives present in the engine oil.

The approx. $1630 \mathrm{~cm}^{-1}$ band is derived from other compounds containing $\mathrm{C}-\mathrm{O}-\mathrm{NO}_{2}$ bonds, resulting from nitrooxidation of engine oil components and fuel in contact with nitrogen oxides. The observed intense $1747 \mathrm{~cm}^{-1}$ band is related to the presence of esters, for which the representative ones are the relations of $\mathrm{C}=\mathrm{O}$ (aliphatic) carbonyl groups with the bands in the $1750-1735 \mathrm{~cm}^{-1}$ range [5].

\section{Conclusions}

1. The presented stages of the diagnostic tests and inference for multi-symptom engine failure states, together with a wide analysis of the recorded error codes, guide the inference procedure towards the correct diagnostic decision.

2. An analysis of X-ray fluorescence spectrum with the energy dispersion in relation to determining the proportion of sedimentary elements, together with the infrared recording of the spectroscopy spectrum showed the proportion of organic compounds in solid PM.

3. Sediment retention leads to improper fuel spraying and dosing in the HPCR system, as well as blocking of the exhaust nozzle lever controllers, resulting in the OBD error code.

4. It is desirable to fully visualize the operating parameters of the interdependent systems and not to focus solely on the direct reading of the error codes indicated by the diagnostic tester.

\section{Nomenclature}

VTG variable turbine geometry

PM particulate matter DPF

HPCRS high pressure common rail system $\quad$ EGR

FAME fatty acid methyl esters diesel particulate filter

exhaust gas recirculation

internal diesel injector deposits

\section{Bibliography}

[1] CAPROTTI, R., BREAKSPEAR, A., KLAUSA, R. RME behaviour in current and future diesel fuel FIE. SAE Technical Paper. 2007, 2007-01-3982.

[2] CAPROTTI, R., BREAKSPEAR, A. et al. Detergency requirements of future diesel injection system. SAE Technical Paper. 2005, 2005-01-3901.

[3] CEC/TC 19 WG24; Report of the ad-hoc incector sticikig task force - 02 August 2011.

[4] CHAPMAN, L. Diesel soap - formation and realeted problems. National Tanks Conference. Boston MA, 2010.

[5] CIESLIKOWSKI, B. Spectral analysis of deposits from a catalytic converter of Diesel engine. Combustion Engines. 2011, 146(3), 1-6.

[6] GUNTER, H. Układy wtryskowe Common Rail w praktyce warsztatowej: budowa, sprawdzanie, diagnostyka. Warszawa. Wyd. Komunikacji i Łączności. 2010.

[7] IDZIOR, M. et al. Analiza wpływu warunków eksploatacji na stan techniczny turbosprężarek doładowanych silników spalinowych. Logistyka. 2011, 3, 1129-1139.
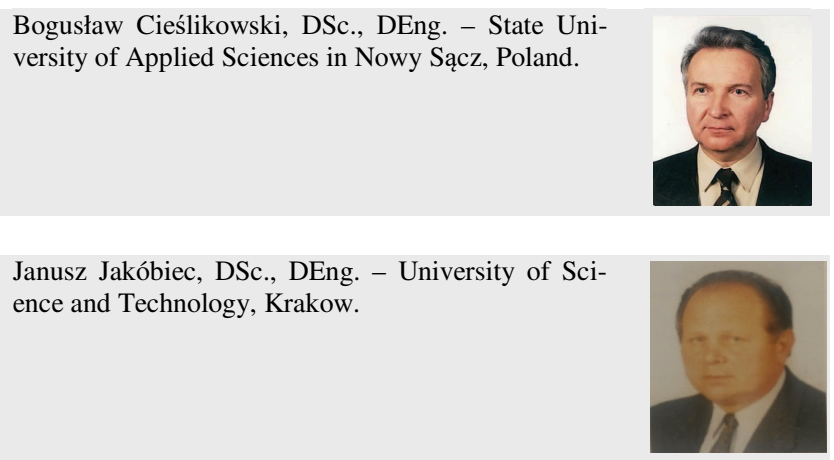

[8] JAKÓBIEC, J., STANIK, W., MAZANEK, A. Olej napędowy wg. Światowej Karty Paliw - wydanie piąte wrzesień 2013. Logistyka. 2014, 3, 96-101.

[9] MERKISZ, J., MAZUREK, S. Pokładowe systemy diagnostyczne pojazdów. Wyd. Komunikacji i Łączności. Warszawa, 2007.

[10] SADLE, J. Spektroskopia molekularna. Wydawnictwa Naukowo Techniczne, Warszawa, 2002.

[11] PREISNER, L. Delta Tech Electronics EDIA5. Materiaty informacyjne Deltatech Electronics, 2011.

[12] STANIK, W., JAKÓBIEC, J. Proekologiczny rozwój technologii silników o zapłonie samoczynnym; AutobusyTechnika-Eksploatacja-Systemy transportowe. 2013, 7-8, 187-192.

[13] STANIK, W., JAKÓBIEC, J., WĄDRZYK, M. Wpływ stabilności termooksydacyjnej biokomponentów na pracę układu wysokociśnieniowego wtrysku paliwa typu Common Rail. Logistyka. 2015, 5, 569-576.

[14] WĘGIEL, S. Zasilanie silników HDI. Poradnik serwisowy. 4. 2004.

[15] WHITE, C., RANDALL, M. Kody usterek. WKiE, Warszawa 2008.

Mariusz Cygnar, DSc., DEng. - State University of Applied Sciences in Nowy Sącz, Poland. 